\title{
La(OTf $)_{3}$ Catalyzed Synthesis of $\alpha$-Aryl Tetrasubstituted Pyrroles through [4+1] Annulation Under Microwave Irradiation
}

\author{
Xue-Min Tan, Qiao-Mei Lai, Zhi-Wei Yang, Xiao Long, Hai-Lin Zhou, Xiao-Lin You, Xiao-Jie Jiang and Hai-Lei Cui* \\ International Academy of Targeted Therapeutics and Innovation, Chongqing University of Arts and Sciences, 319 Honghe Ave., Yongchuan,
}

Chongqing 402160, P.R. China; E-mail: cuihailei616@163.com

Abstract $\mathrm{ALa}(\mathrm{OTf})_{3}$ catalyzed synthesis of tetrasubstituted pyrroles under microwave irradiation has been developed affording various $\alpha$-aryl tetrasubstituted pyrroles in acceptable to good yields (36-82\% yield) through condensation/alkyne azacyclization/isomerization sequence. Functionalized $\alpha$-aryl pentasubstituted pyrroles could be prepared from tetrasubstituted pyrroles through easy transformations.

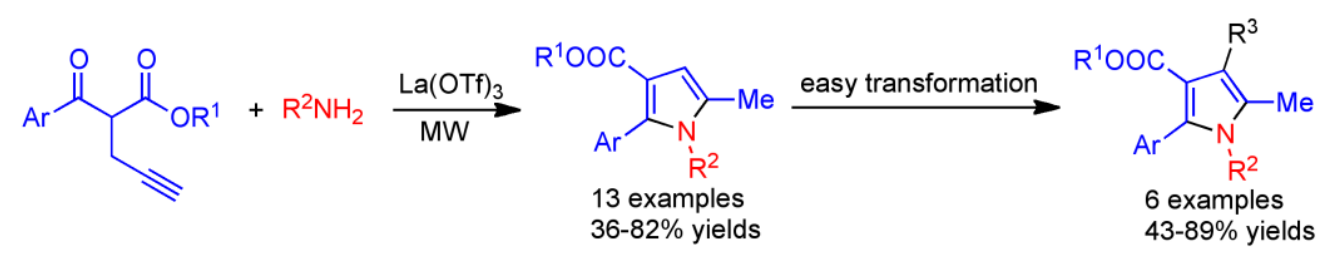

Keywords: annulation, alkyne, tetrasubstituted pyrrole, microwave, pentasubstituted pyrrole

Pyrrole is an important structural motif that could be found in a large number of natural products, drug molecules and synthetic bioactive molecules. ${ }^{1}$ Among this class of heterocycles, $\alpha$-aryl polysubstituted pyrroles are extremely attractive because of their frequent occurrence in biological compounds (Figure 1). ${ }^{2}$ For example, Atorvastatin is an HMG-CoA inhibitor and used for the treatment of dyslipidemia; ${ }^{2 a, 2 b}$ URB 447 is a selective FAAH inhibitor; ${ }^{2 \mathrm{c}} \mathrm{BM} 212$ was found to be a potent antimycobacterial agent. ${ }^{2 \mathrm{~d}}$ The development of efficient synthesis of ploysubstituted pyrroles has attracted tremendous attention in the fields of medicinal chemistry and synthetic chemistry owing to their great importance. Very recently, many elegant methodologies have been developed to construct highly substituted pyrroles ${ }^{3}$, such as multicomponent reactions ${ }^{4}$, C-H bond activation ${ }^{5}$, 1,3-dipolar cycloaddition ${ }^{6}$, oxidative cross-coupling/cyclization ${ }^{7}$, and rearrangement cascade. ${ }^{8}$ However, in spite of the existence of a wide range of excellent synthetic methods, the construction of diversified libraries of pyrroles amenable to pharmaceutical research 
and for lead optimization is still chanlleging. Thus, development of more convenient methods to allow access to structurally diversified pyrroles using readily accessible material is extremely desirable.

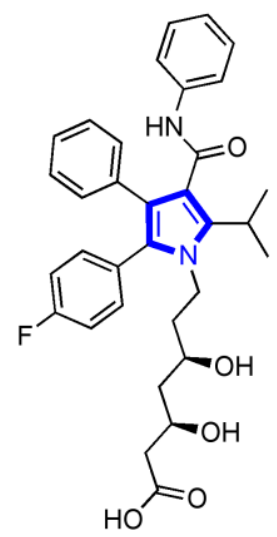

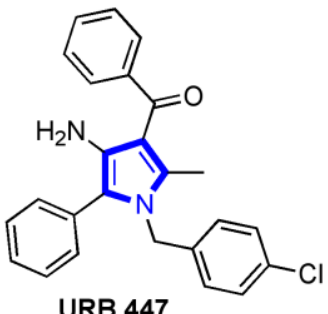

URB 447<smiles>COc1ccc(-c2cc(C#N)c(C)n2-c2ccc(F)cc2)cc1</smiles>

COX-2 selective NSAID

Atorvastatin (Lipitor)

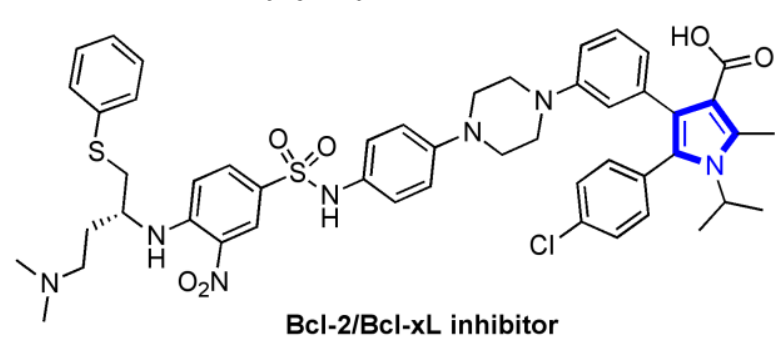<smiles>Cc1c(CN2CCN(C)CC2)cc(-c2ccc(Cl)cc2)n1-c1ccc(Cl)cc1</smiles>

Figure 1. Natural products and synthetic bioactive compounds bearing $\alpha$-aryl tetrasubstituted pyrroles.

Recently, alkyne azacyclization-based [4+1] annulation has shown broad application in the synthesis of multisubstituted pyrroles. ${ }^{9} \mathrm{Bi}$, Zhang and co-workers developed a highly efficient iron-catalyzed $[4 \mathrm{C}+1 \mathrm{~N}]$ cyclization leading to the synthesis of a variety of tetra- and fully-substituted pyrroles in good yields. ${ }^{9 a}$ The preparation of multisubstituted pyrroles via propargylation/cycloisomerization sequence has been achieved by Roy group and Zheng group by employing Ir-Sn bimetallic catalyst and $\mathrm{AgSbF}_{6}$ respectively. ${ }^{9 b, 9 c}$ Tsuji and Nakamura reported their development of Indium-catalyzed synthesis of ploysubstituted pyrroles via [4+1] annulation strategy. ${ }^{9 \mathrm{~d}}$ Zhan group developed a facile chemoselective copper-promoted synthesis of polysubstituted pyrroles through the formation of 1,4-diynes as key intermediates from propargyl alcohols and terminal alkynes. ${ }^{9 e}$ In our previous study, our group disclosed a tandem copper-catalyzed propargylation/alkyne azacyclization/isomerization reaction to synthesize fully substituted pyrroles, especially $\alpha$-aryl pentasubstituted pyrroles, from 
$\beta$-enamino compounds and propargyl acetates. ${ }^{10}$ We hypothesized that 2-propynyl-1,3-dicarbonyl compounds would react with amines in the presence of metal catalyst to deliver tetrasubstituted pyrroles through condensation/alkyne azacyclization/isomerization sequence. As part of our continuing efforts to construct heterocycles through metal-catalyzed tandem propargylation/alkyne cyclization cascade, we report here our work of microwave assisted and $\mathrm{La}(\mathrm{OTf})_{3}$ catalyzed synthesis of tetrasubstituted pyrroles and their easy transformations to fully substituted pyrroles (Scheme 1).
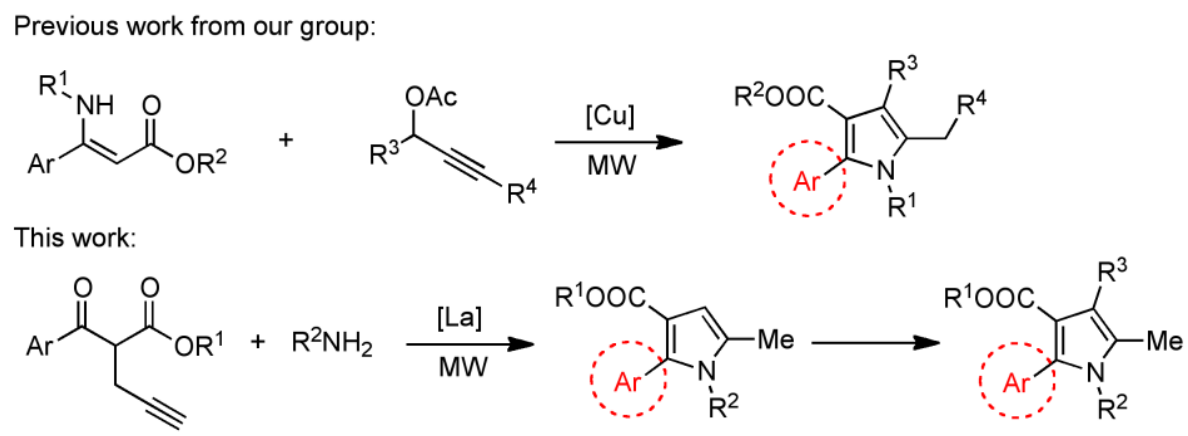

\section{Scheme 1. Design of $\alpha$-aryl tetrasubstituted and fully substituted pyrroles synthesis.}

Our study centered on Lewis acid catalyzed condensation and subsequent alkyne azacyclization to yield tetrasubstituted pyrrole. Accordingly, we evaluated the efficiency of Lewis acid, ligand, substrate ratio, and solvent. We chose propargylated $\beta$-ketoester 1a and amine $\mathbf{1 b}$ as model substrates. In order to avoid the competitive reaction of oxacyclization ${ }^{11}$, excess amount of amine was used at first. As shown in Table 1 , screen of Lewis acid and solvents demonstrated that $\mathrm{La}(\mathrm{OTf})_{3}$ and $\mathrm{PhCF}_{3}$ are most effective as catalyst and solvent respectively (entries 1-9). Surprisingly, copper salts only give poor yields and are not as effective as that in the microwave assisted synthesis of pyrrole with $\beta$-enamino compounds and propargyl acetates. ${ }^{10}$ Ligands were then tested in order to improve the yield and $\mathrm{PPh}_{3}$ was found to be the best choice (entries 10-13). Further optimization demonstrates that the use of 2 equivalents of amine gives the best yield (entries 14-16). We also investigated if any positive effect could be achieved on yield by lowering reaction temperature. However, poor yield and conversion were observed when the reaction was carried out at $120{ }^{\circ} \mathrm{C}$ (entry 17). Decreased catalyst amount resulted in reduced yield too (entry 18 ). 
Table 1

Optimization results ${ }^{\mathrm{a}, \mathrm{b}}$

\begin{tabular}{lllll} 
& & & \\
\hline
\end{tabular}

${ }^{a}$ Unless otherwise noted, reaction was performed with $0.1 \mathrm{mmol}$ of $\mathbf{1 a}, 0.3 \mathrm{mmol}$ of $\mathbf{2 a}, 20 \mathrm{~mol} \%$ of catalyst and $80 \mathrm{~mol} \%$ of additive in $1.0 \mathrm{~mL}$ of solvent irradiated by microwave at $150{ }^{\circ} \mathrm{C}$ for 30 minutes.

${ }^{\mathrm{b}}$ Yield was determined by ${ }^{1} \mathrm{H}$ NMR with $\mathrm{CH}_{2} \mathrm{Br}_{2}$ as internal standard.

${ }^{\mathrm{c}}$ With $40 \mathrm{~mol} \%$ of additive.

${ }^{\mathrm{d}}$ With $0.2 \mathrm{mmol}$ of 1a, $0.4 \mathrm{mmol}$ of $\mathbf{2 a}, 20 \mathrm{~mol} \%$ of $\mathrm{La}(\mathrm{OTf})_{3}$ and $80 \mathrm{~mol} \%$ of $\mathrm{PPh}_{3}$ in $1.0 \mathrm{~mL}$ of $\mathrm{PhCF}_{3}$.

${ }^{\mathrm{e}}$ At $120{ }^{\circ} \mathrm{C}$.

${ }^{\mathrm{f}}$ With $0.2 \mathrm{mmol}$ of 1a, $0.4 \mathrm{mmol}$ of $\mathbf{2 a}, 10 \mathrm{~mol} \%$ of $\mathrm{La}(\mathrm{OTf})_{3}$ and $40 \mathrm{~mol} \%$ of $\mathrm{PPh}_{3}$ in $1.0 \mathrm{~mL}$ of $\mathrm{PhCF}_{3}$.

As we obtained the optimized reaction conditions, we then examined the substrate scope. As shown in Table 2, aliphatic amines could be applied successfully in this catalytic system. 4-Methoxybenzylamine, 2-furylmethylamine, tryptamine, isobutylamine, methoxyethylamine, 4-morpholinepropylamine, and cyclopropylamine gave corresponding tetrasubstituted pyrroles in moderate to good yields (62-82\%). The use of $p$-anisidine led to slightly decreased yield (57\%) even with prolonged reaction 
time probably due to its poor reactivity. Product $3 \mathbf{i}$ was failed to obtain probably because of methoxy group at 2-position hindering condensation. Electron-donating groups at 3 and 4 positions of the aromatic ring of 2-propynyl-1,3-dicarbonyl compounds have little influence on yields. Propargylated $\beta$-ketoester bearing bromo substituted ring delivered product $\mathbf{3 m}$ in $36 \%$ yield. Decreased yield (39\%) was also observed when methyl 2-(furan-2-carbonyl)pent-4-ynoate was submitted to this system. Corresponding pyrrole 3o was not detected when substrate bearing internal alkyne was applied. It shows the limitation of this catalytic system. Alkylated 2-propynyl-1,3-dicarbonyl compound could also be tolerant in this catalytic system affording compound $3 p$ in $70 \%$ yield.

\section{Table 2}

Examination of substrate scope $\mathrm{e}^{\mathrm{a}, \mathrm{b}}$ 

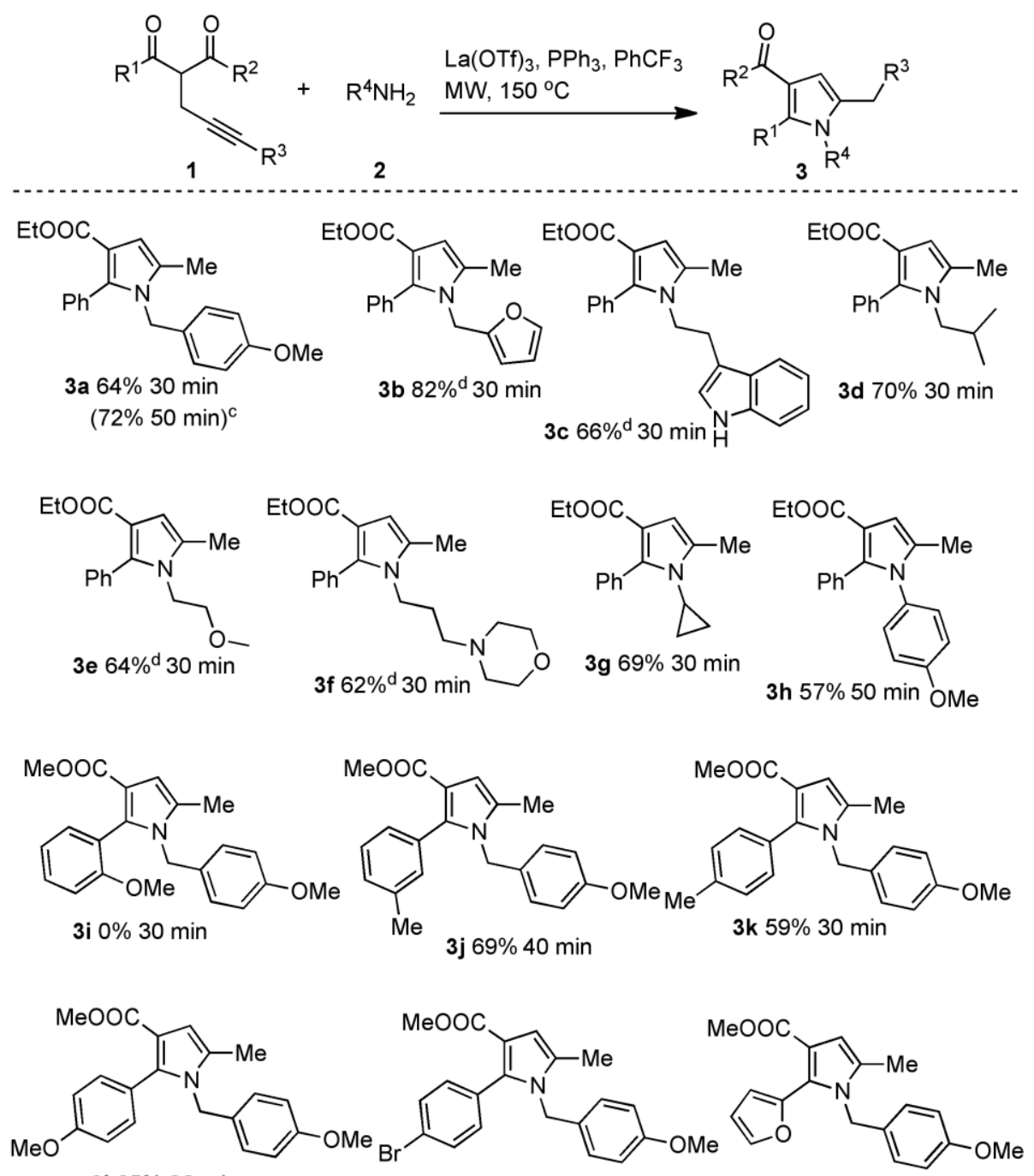

$3165 \% 30 \mathrm{~min}$

$3 \mathrm{~m} 36 \% 30 \mathrm{~min}$

3 n $39 \% 30$ min
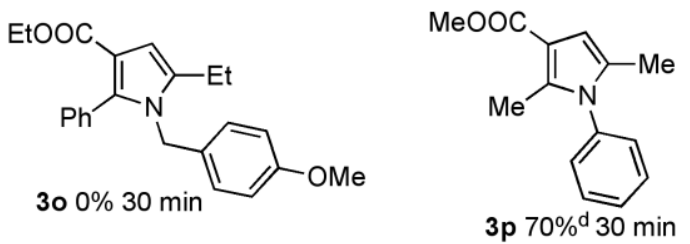

${ }^{\mathrm{a}}$ Unless otherwise noted, reaction was performed with $0.2 \mathrm{mmol}$ of $1 \mathrm{a}, 0.4 \mathrm{mmol}$ of $2 \mathbf{a}, 20 \mathrm{~mol} \%$ of $\mathrm{La}(\mathrm{OTf})_{3}$ and $80 \mathrm{~mol} \%$ of $\mathrm{PPh}{ }_{3}$ in $1.0 \mathrm{~mL}$ of $\mathrm{PhCF}_{3}$ irradiated under microwave at $150{ }^{\circ} \mathrm{C}$.

${ }^{\mathrm{b}}$ Isolated yield.

${ }^{\mathrm{c}}$ With $0.4 \mathrm{mmol}$ of $\mathbf{1 a}, 0.8 \mathrm{mmol}$ of $\mathbf{2 a}$.

${ }^{\mathrm{d}}$ With $0.4 \mathrm{mmol}$ of $\mathbf{1 a}, 0.2 \mathrm{mmol}$ of $\mathbf{2 a}$.

In order to get more evidence for mechanism proposal, we performed control experiments (Scheme 2). In contrast to the catalytic system with copper catalyst developed previously to synthesize dihydrofurans and furans, no reaction occurred in the absence of amine under the current conditions. This indicates that $\mathrm{La}(\mathrm{OTf})_{3}$ is not an effective promoter for alkyne 
oxacyclization as copper or indium salts. ${ }^{9 \mathrm{~d}, 11}$ Without catalyst, no desired product or other intermediate was observed. When compounds 1a and 2a were treated under the catalytic system in the presence of $\mathrm{D}_{2} \mathrm{O}$, the deuterium labelled product $\mathbf{3 a - D}$ was isolated in 52\% yield. 63\% and 56\% deuteriums at 4 position and 5-methyl group of pyrrole ring were observed respectively indicating an allenyl intermediate may be involved and protonation/isomerization sequence occurred in this process.
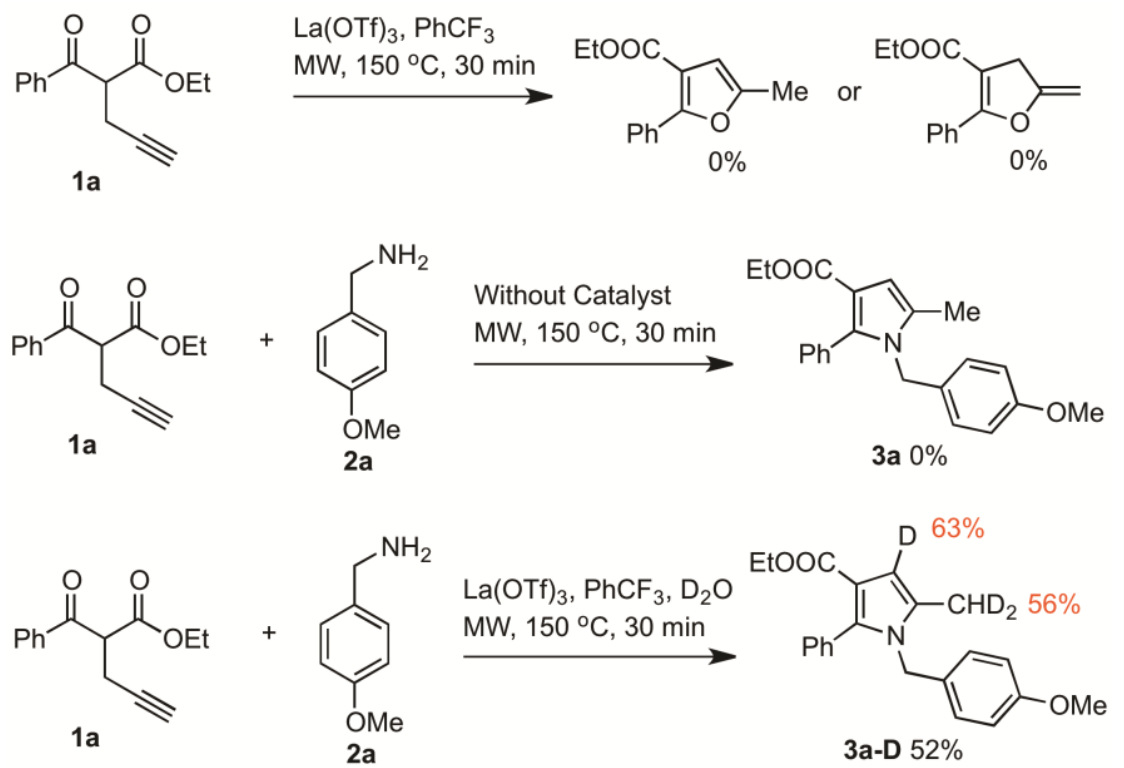

Scheme 2. Control experiments and deuterium labeling study.

On the basis of our results and previous reports, we proposed a possible mechanism for this [4+1] annulation. Firstly $\mathrm{La}(\mathrm{OTf})_{3}$ acts as a Lewis acid to promote the condensation of propargylated $\beta$-ketoester $\mathbf{1}$ and amine $\mathbf{2}$. Then 5-exo-dig cyclization occurs through alkyne $\pi$-activation. The following protonation of intermediate $\mathbf{C}$ and isomerization of intermediate $\mathbf{D}$ give tetrasubstituted pyrrole. As product 3a-D was obtained in deuterium labeling study (Scheme 3), equilibrium between intermediate $\mathbf{A}$ bearing allenyl group and intermediate $\mathbf{B}$ bearing alkyne group may be involved in this catalytic cycle. 

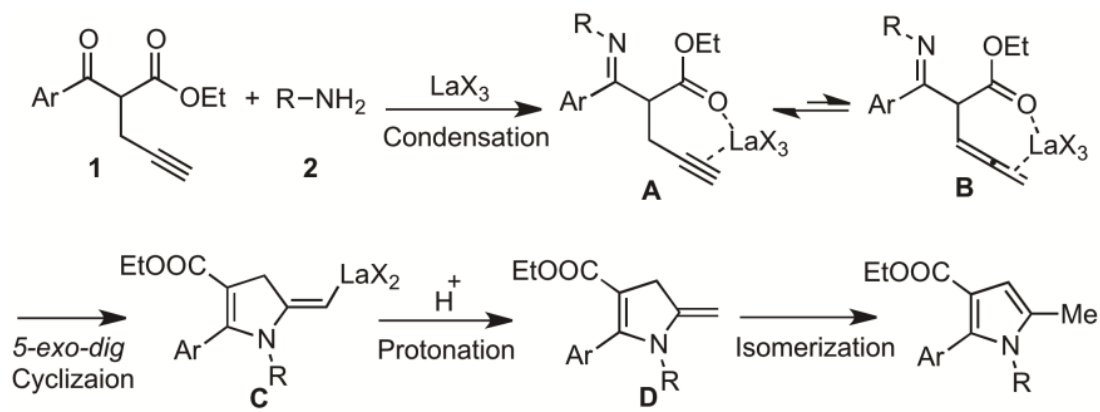

Scheme 3. Proposed mechanism.

Fully substituted pyrroles show a wide range of bioactivities ${ }^{1,12}$, but there are few methods available for easy assembly of functionalized fully substituted pyrroles, especially $\alpha$-aryl pentasubstituted pyrroles. ${ }^{13}$ In order to demonstrate the utilization of our method, we tried to realize easy preparation of fully substituted pyrroles from tetrasubstituted pyrrole through simple chemical transformations. As shown in Scheme 4, compounds 5 and $\mathbf{6}$ could be obtained by Vilsmeier-Haack reaction and Mannich reaction respectively in good yields (82\% and 67\%). Bromination of 3a with NBS and a following Suzuki coupling gave $\alpha, \gamma$-diarylated pyrrole $\mathbf{8}$ in good yield (77\% totally). Olefination of compound 3a could be achieved by Oxidative Heck reactions leading to functionalized pyrroles $\mathbf{9}$ and $\mathbf{1 0}$ in $43 \%$ and $70 \%$ yields respectively. 


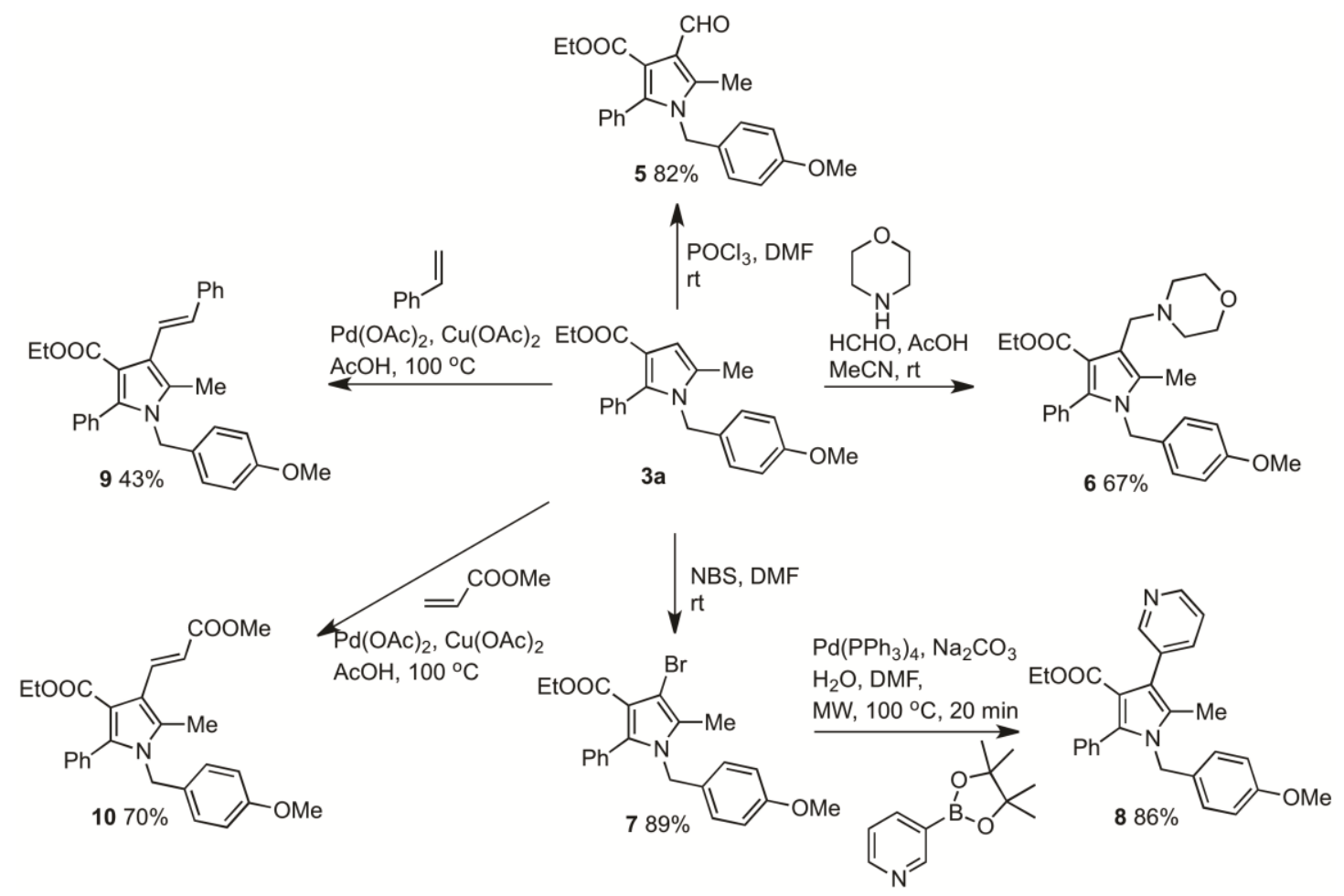

Scheme 4. Transformations to fully substituted pyrroles.

In conclusion, we have developed a $\mathrm{La}(\mathrm{OTf})_{3}$ catalyzed synthesis of tetrasubstituted pyrroles under microwave irradiation.

Various $\alpha$-aryl tetrasubstituted pyrroles could be afforded in acceptable to good yields using readily available materials (36-82\%). Based on our results and previous reports we proposed that this reaction undergoes through condensation/alkyne azacyclization/isomerization sequence. Functionalized $\alpha$-aryl pentasubstituted pyrroles could be prepared from tetrasubstituted pyrroles through easy transformations.

\section{Acknowledgements}

We are grateful for the support provided for this study by the National Science Foundation of China (21502013), the Scientific and Technological Research Program of the Chongqing Municipal Education Commission (KJ1501111), and Chongqing University of Arts and Sciences (R2015BX01). 


\section{Supplementary data}

Supplementary data (experimental procedures, characterization data, and copies of ${ }^{1} \mathrm{H}$ NMR and ${ }^{13} \mathrm{C}$ NMR spectra for all new compounds) associated with this article can be found.

\section{References and notes}

1. (a) Bass, P. D. ; Gubler, D. A. ; Judd, T. C. ; Williams, R. M. Chem. Rev. 2013, 113, 6816. (b) Walsh, C. T.; Garneau-Tsodikova, S.; Howard-Jones, A. R. Nat. Prod. Rep. 2006, 23, 517. (c) Fan, H.; Peng, J.; Hamann, M. T.; Hu, J.-F. Chem. Rev. $2008,108,264$.

2. (a) Roth, B. D. ; Mich, A. A. U.S. Patent 4681893, 1987. (b) Roth, B. D. ; Mich, A. A. U.S. Patent 5273995, 1991. (c) LoVerme, J. ;

Duranti, A. ; Tontini, A. ; Spadoni, G. ; Mor, M. ; Rivara, S. ; Stella, N. ; Xu, C. ; Tarzia, G. ; Piomelli, D. Bioorg. Med. Chem. Lett. 2009, 19, 639. (d) Biava, M. ; Porretta, G. C. ; Deidda, D. ; Pompei, R. ; Tafi, A. ; Manetti, F. Bioorg. Med. Chem. 2004, 12, 1453. (e) Zhou, H.; Aguilar, A.; Chen, J.; Bai, L.; Liu, L.; Meagher, J. L.; Yang, C.-Y.; McEachern, D.; Cong, X.; Stuckey, J. A.; Wang, S. J. Med. Chem. 2012, 55, 6149. (f) Cossio Mora, F. P. ; Esteller Badosa, M. ; Zubia Olascoaga, A. ; Otaegui Ansa, D. European Patent EP1975158, 2005. (g) Biava, M.; Porretta, G. C.; Poce, G.; Supino, S.; Deidda, D. Pompei, R.; Molicotti, P.; Manetti, F.; Botta, M.; J. Med. Chem. 2006, 49, 4946.

3. For reviews, see: (a) Gulevich, A. V. ; Dudnik, A. S. ; Chernyak, N. ; Gevorgyan, V. Chem. Rev. 2013, 113, 3084. (b) Estévez, V.; Villacampa, M.; Menéndez, J. C. Chem. Soc. Rev. 2010, 39, 4402. (c) Young, I. S. ; Thornton, P. D. ; Thompson, A. Nat. Prod. Rep. 2010, 27, 1801. (d) Lu, L.-Q.; Chen, J.-R.; Xiao, W.-J. Acc. Chem. Res. 2012, 45, 1278. (e) Ackermann, L.; Vicente, R.; Kapdi, A. R. Angew. Chem., Int. Ed. 2009, 48, 9792. (f) Zhou, N.-N.; Zhu, H.-T.; Yang, D.-S.; Guan, Z.-H. Org. Biomol. Chem. $2016,14,7136$.

4. (a) Morin, M. S. T.; St-Cyr, D. J.; Arndtsen, B. A. Org. Lett. 2010, 12, 4916. (b) Sha, Q.; Arman, H.; Doyle, M. P. Org. Lett. 2015, 17, 3876. (c) Dhara, D.; Gayen, K. S.; Khamarui, S.; Pandit, P.; Ghosh, S.; Maiti, D. K. J. Org. Chem. 2012, 77, 10441. (d) Liu, X.-t. ; Huang, L. ; Zheng, F.-j. ; Zhang, Z.-p. Adv. Synth. Catal. 2008, 350, 2778. (e) Cadierno, V. ; Gimeno, J. ; Nebra, N. Chem.-Eur. J. 2007, 13, 9973. (f) Liu, P.; Liu, J.-1.; Wang, H.-s.; Pan, Y.-m.; Liang, H.; Chen, Z.-F. Chem. Commun. 2014, 50, 4798. (g) Dhawan, R.; 
Arndtsen, B. A. J. Am. Chem. Soc. 2004, 126, 468. (h) Trost, B. M.; Lumb, J.-P.; Azzarelli, J. M. J. Am. Chem. Soc. 2011 , 133, 740.

5. (a) Rakshit, S.; Patureau, F. W.; Glorius, F. J. Am. Chem. Soc. 2010, 132, 9585. (b) Kim, D.-S.; Seo, Y.-S.; Jun, C.-H. Org. Lett. 2015, 17, 3842 .

6. (a) Lu, Y.; Arndtsen, B. A. Angew. Chem., Int. Ed. 2008, 47, 5430. (b) Li, Y.-J.; Huang, H.-M.; Dong, H.-Q.; Jia, J.-H.; Han, L.; Ye, Q.; Gao, J.-R. J. Org. Chem. 2013, 78, 9424.

7. (a) Ke, J.; He, C.; Liu, H.; Li, M.; Lei, A. Chem. Commun. 2013, 49, 7549. (b) Lida, K.; Miura, T.; Ando, J.; Saito, S. Org. Lett. 2013, 15, 1436. (c) Tang, X.; Huang, L.; Qi, C.; Wu, W.; Jiang, H. Chem. Commun. 2013, 49, 9597. (d) Zhao, M.; Wang, F.; Li, X. Org. Lett. 2012, 14, 1412.

8. (a) Jiang, Y.; Chan, W. C.; Park, C.-M. J. Am. Chem. Soc. 2012, 134, 4104. (b) Binder, J. T.; Kirsch, S. F. Org. Lett. 2006,8 , 2151. (c) Zhao, X.; Zhang, E.; Tu, Y.-Q.; Zhang, Y.-Q.; Yuan, D.-Y.; Cao, K.; Fan, C.-A.; Zhang, F.-M. Org. Lett. $2009,11,4002$.

9. (a) Wang, Y.; Bi, X.; Li, D.; Liao, P.; Wang, Y.; Yang, J.; Zhang, Q.; Liu, Q. Chem. Commun. 2011, 47, 809. (b) Chatterjee, P. N. ; Roy, S. Tetrahedron 2011, 67, 4569. (c) Gujarathi, S.; Liu, X. ; Song, L.; Hendrickson, H.; Zheng, G. Tetrahedron 2014, 70, 5267. (d) Tsuji, H.; Yamagata, K.-i.; Ueda, Y.; Nakamura, E. Synlett. 2011, 7, 1015. (e) Wang, T.; Chen, X.-1.; Chen, L.; Zhan, Z.-p. Org. Lett. 2011, 13, 3324.

10. Zhang, X,-Y.; Yang, Z.-W.; Chen, Z.-Z.; Wang, J.; Yang, D.-L.; Shen, Z.; Hu. L.-L.; Xie, J.-W.; Zhang, J.; Cui, H.-L. J. Org. Chem. 2016, 81,1778 .

11. Chen, Y.-F.; Wang, H.-F.; Wang, Y.; Luo, Y.-C.; Zhu, H.-L.; Xu, P.-F. Adv. Synth. Catal. 2010, $352,1163$.

12. (a) Boger, D. L.; Boyce, C. W.; Labroli, M. A.; Sehon, C. A.; Jin, Q. J. Am. Chem. Soc. 1999, 121, 54. (b) Rudi, A.; Goldberg, I.; Stein, Z.; Frolow, F. ; Benayahu, Y.; Schleyer, M.; Kashman, Y. J. Org. Chem. 1994, 59, 999.

13. For recent examples on the synthesis of fully substituted pyrroles and tetrasubstituted pyrroles, see: (a) Tan, W. W.; Yoshikai, N. Chem. Sci. 2015, 6, 6448. (b) Li, B.-L.; Hu, H.-C.; Mo, L.-P.; Zhang, Z.-H. RSC Adv. 2014, 4, 12929. (c) Guan, Z.-H.; Li, L.; Ren, Z.-H.; Li, J.; Zhao, M.-N. Green. Chem. 2011, 13, 1664. (d) Sugimoto, K.; Yamamoto, N.; Tominaga, D.; Matsuya, Y. Org. Lett. 2015, 
17, 1320. (e) Attanasi, O. A.; Favi, G.; Mantellini, F.; Moscatelli, G.; Santeusanio, S. J. Org. Chem. 2011, 76, 2860. (f) Yan, R.-L.; Luo, J.; Wang, C.-X.; Ma, C.-W.; Huang, G.-S.; Liang, Y.-M. J. Org. Chem. 2010, 75, 5395. (g) Wang, X.; Xu, X.-P.; Wang, S.-Y.; Zhou, W.; Ji, S.-J. Org. Lett. 2013, 15, 4246. (h) Wang, Y.; Jiang, C.-M.; Li, H.-L.; He, F.-S.; Luo, X.; Deng, W.-P. J. Org. Chem. 2016, 81, 8653. (i) Han, S.; Zard, S. Z. Org. Lett. 2014, 16, 1992. (j) Cai, Y.; Jalan, A.; Kubosumi, A. R.; Castle, S. L. Org. Lett. 2015, 17, 488. 
$\mathrm{La}(\mathrm{OTf})_{3}$ Catalyzed Synthesis of $\alpha$-Aryl Tetrasubstituted Pyrroles through [4+1] Annulation Under Microwave Irradiation

Xue-Min Tan, Qiao-Mei Lai, Zhi-Wei Yang, Xiao Long, Hai-Lin Zhou, Xiao-Lin You, Xiao-Jie Jiang, Hai-Lei Cui*

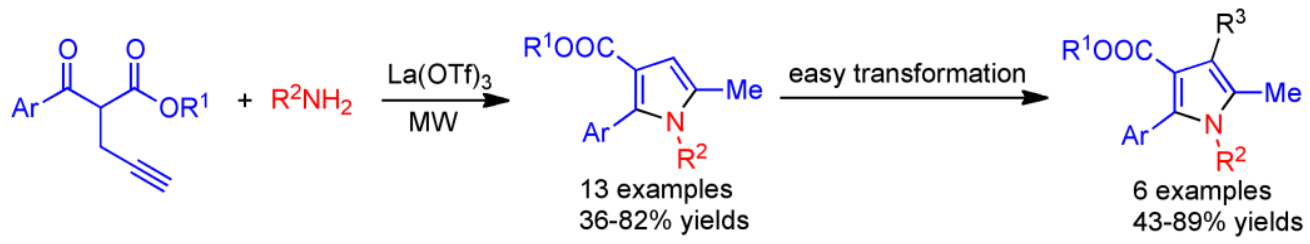

